\title{
TITLE:
}

\section{Over-voltage suppression in a fault current limiter by a $\mathrm{ZnO}$ varistor}

\section{$\operatorname{AUTHOR}(\mathrm{S})$ :}

Shirai, Y; Miyato, Y; Taguchi, M; Shiotsu, M; Hatta, H; Muroya, S; Chiba, M; Nitta, T

\section{CITATION:}

Shirai, Y...[et al]. Over-voltage suppression in a fault current limiter by a ZnO varistor. IEEE TRANSACTIONS ON APPLIED SUPERCONDUCTIVITY 2003, 13(2): 2064-2067

\section{ISSUE DATE:}

2003-06

URL:

http://hdl.handle.net/2433/50261

\section{RIGHT:}

(c)2003 IEEE. Personal use of this material is permitted. However, permission to reprint/republish this material for advertising or promotional purposes or for creating new collective works for resale or redistribution to servers or lists, or to reuse any copyrighted component of this work in other works must be obtained from the IEEE. 


\title{
Over-Voltage Suppression in a Fault Current Limiter by a $\mathrm{ZnO}$ Varistor
}

\author{
Y. Shirai, Member, IEEE, Y. Miyato, M. Taguchi, M. Shiotsu, H. Hatta, S. Muroya, M. Chiba, and \\ T. Nitta, Member, IEEE
}

\begin{abstract}
A Superconducting Fault Current Limiter (SCFCL) of the transformer type with a ZnO varistor (Metal Oxide Varistor) in parallel was investigated to determine the effects of the $\mathrm{ZnO}$ varistor as an over-voltage suppressor for the SCFCL. A SCFCL of the transformer type, which has an adjustable trigger current level, has been studied. A small model of this type of SCFCL was designed and built with NbTi superconductors. Since a fault current is reduced by its inductive component, a large over-voltage is observed at the beginning of the current limiting event. It is important to suppress the over-voltage to avoid any damages to the power system apparatus. Experimental results on the fault current limiting operation of the SCFCL with $\mathrm{ZnO}$ varistor in parallel are shown. It was confirmed that the surge voltage that appears at the terminal of the SCFCL can be successfully suppressed by $\mathrm{ZnO}$ varistor. Current limiting and recovery characteristics of the SCFCL with a $\mathrm{ZnO}$ varistor are investigated and discussed. The trigger current level of the SCFCL is not affected by the $\mathrm{ZnO}$ varistor. The recovery time is a little longer with the $\mathrm{ZnO}$ varistor than that without it. Energy dissipation in the $\mathrm{ZnO}$ varistor and the SCFCL is discussed.
\end{abstract}

Index Terms-Over-voltage suppression, superconducting fault current limiter, $\mathrm{ZnO}$ varistor.

\section{INTRODUCTION}

$\mathbf{S}$ UPERCONDUCTING fault current limiters (SCFCLs) are expected to improve reliability and stability of power systems. Many studies have been performed with various types of SCFCLs [1]-[4]. The operating characteristics of SCFCL's have been investigated.

The important specifications of the SCFCL as a power system component are the trigger current level, the limiting impedance and the recovery time. From this point of view, we have proposed an SCFCL of the transformer type with an adjustable trigger current level. A prototype single-phase unit has been designed and built [5]. The fault current is limited by the inductance of the primary coil. Therefore, the amount of energy dissipation in the secondary superconducting wire is small in the prototype SCFCL. The recovery time (the required zero-cur-

Manuscript received August 5, 2002. This work was supported in part by the Japan Society for the Promotion of Science under Project JSPS-RFTF97P01004.

Y. Shirai, Y. Miyato, T. Taguchi, and M. Shiotsu are with the Department of Energy Science and Technology, Kyoto University, Yoshida-Honmachi, Sakyo-ku, Kyoto, 606-8501 Japan (e-mail: shirai@energy.kyoto-u.ac.jp; miyato@energy.kyoto-u.ac.jp; taguchi@energy.kyoto-u.ac.jp; shiotsu@energy.kyoto-u.ac.jp).

T. Hatta, S. Muroya, M. Chiba, and T. Nitta are with the Department of Electrical Engineering, the University of Tokyo, Tokyo, 113-8656 Japan (e-mail: hatta@asc.t.u-tokyo.ac.jp; muroya@asc.t.u-tokyo.ac.jp; chiba@asc.t.u-tokyo.ac.jp; nitta@asc.t.u-tokyo.ac.jp).

Digital Object Identifier 10.1109/TASC.2003.812987

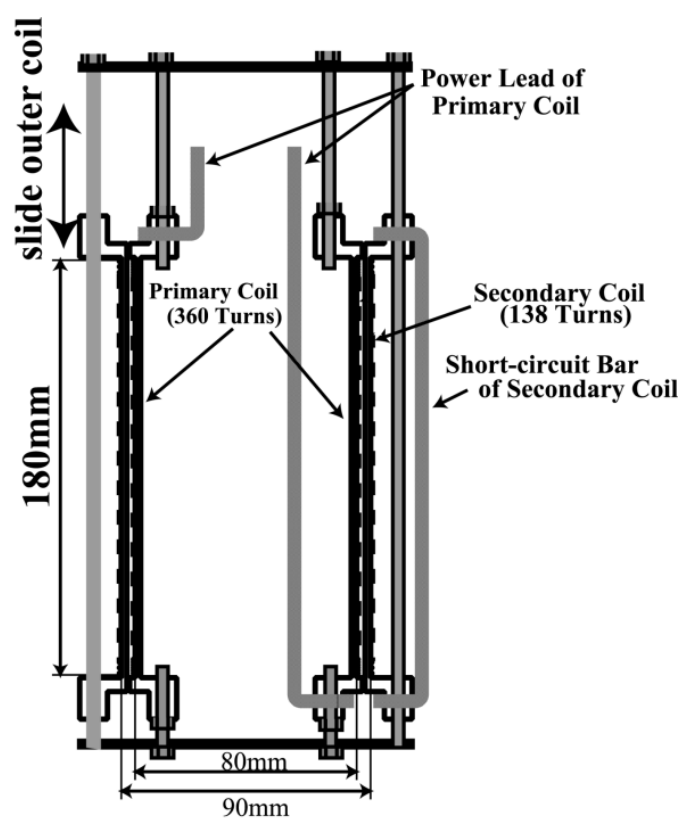

Fig. 1. Schematic configuration of the proposed SCFCL.

rent time for successful recovery from current limiting mode to waiting mode) is rather short, $450 \mathrm{~ms}$ at most [6], [7]. As the next step, a three-phase SCFCL of the proposed type was designed and built [8]. Experimental studies on the power system characteristics of the SCFCL were carried out using artificial transmission lines and a generator [9].

One of the serious problems that has to be solved is an overvoltage that appears across the SCFCL at the beginning of current limiting. It may seriously damage the rest of the power system components. In this paper, the operating characteristics of the SCFCL with a parallel $\mathrm{ZnO}$ varistor (which is usually used as an arrester), are studied by use of a trial model. The performance of the $\mathrm{ZnO}$ varistor to suppress the over-voltage was investigated by experimental and simulation studies.

\section{EXPERIMENT OF OVER-VOLTAGE SUPPRESSION BY A ZnO VARISTOR}

\section{A. Prototype SCFCL}

The prototype SCFCL unit for three-phase operation was designed and built. It contains three transformer type SCFCLs in one cryostat. We used only one of the SFCFL for this study. The SCFCL consists of two superconducting coils (NbTi wire for AC use) coupled co-axially. The inner (primary) coil will be connected to a power line as shown in Fig. 1. The outer 


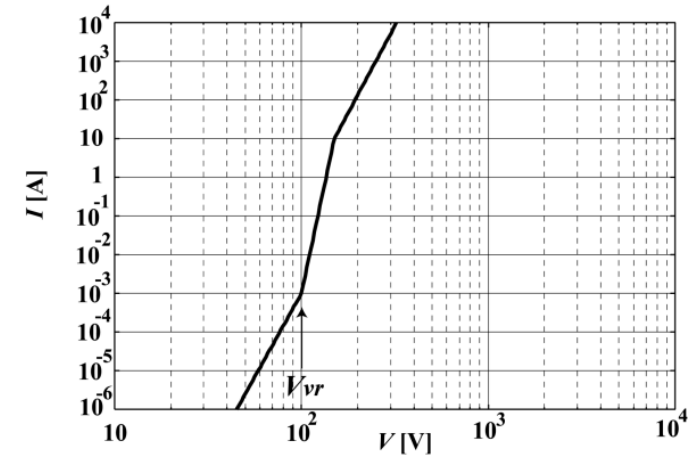

Fig. 2. Voltage-current characteristic model of typical $\mathrm{ZnO}$ varistor.

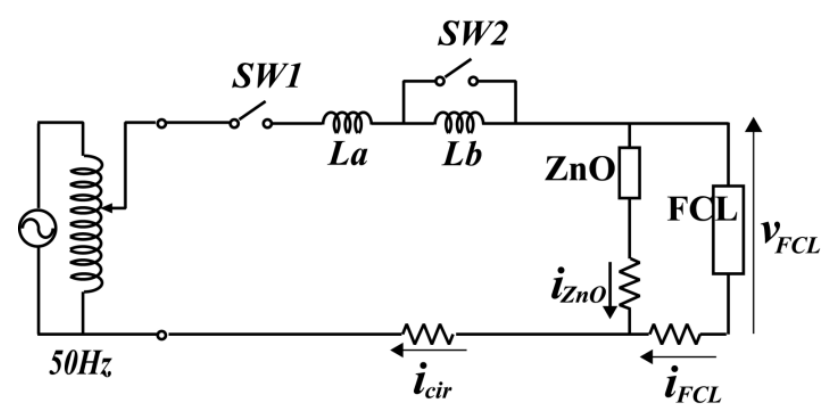

Fig. 3. Experimental circuit for over-voltage suppression across the SCFCL by use of $\mathrm{ZnO}$ varistor.

(secondary) coil is short-circuited. The secondary coil can be slid a small distance in order to adjust the trigger current level [10]. The primary coil inductance $\boldsymbol{L}_{1}$, that is the limiting inductance, is $3.82 \mathrm{mH}$, the secondary coil inductance $\boldsymbol{L}_{2}$ is $0.69 \mathrm{mH}$ and the mutual inductance $M$ is $1.43 \mathrm{mH}$. The coils were designed so that the super-normal transition occurs only at the secondary wire, when the fault current flowing through the SCFCL reaches the trigger current level. The fault current is limited by the reactance of the primary coil. The over-voltage appeared across the primary coil because of the sudden change (less than sub-milliseconds) of the reactance of the SCFCL.

\section{B. ZnO Varistor}

Metal Oxide Varistors, especially $\mathrm{ZnO}$ varistors, are usually introduced into power systems to suppress lightning surge voltages. The typical voltage-current characteristic is shown in Fig. 2. The varistor voltage $\boldsymbol{V}_{v r}$ is defined as the voltage at the $1 \mathrm{~mA}$ of current flow, that is, $100 \mathrm{~V}$ in this case. When the voltage across the $\mathrm{ZnO}$ varistor exceeds $\boldsymbol{V}_{v r}$, the resistance changes to small values drastically. Thus, the over-voltage is clipped to the varistor voltage.

\section{Experimental Circuit}

The experimental circuit for over-voltage suppression across the SCFCL by use of a $\mathrm{ZnO}$ varistor is shown in Fig. 3. Inductances $\boldsymbol{L}_{a}$ and $\boldsymbol{L}_{b}$ of reactors $\boldsymbol{a}$ and $\boldsymbol{b}$ are $2.13 \mathrm{mH}$ and $6.40 \mathrm{mH}$, respectively. The AC voltage source $210 \mathrm{~V}(50 \mathrm{~Hz})$ is stepped down to $100 \mathrm{~V}$ and applied to the test circuit. The magnetically controlled switch $S W_{\mathbf{1}}$ is closed and $S W_{\mathbf{2}}$ is open in the initial state. $\boldsymbol{S W}_{\mathbf{2}}$ is closed to simulate a fault. The phase at the fault occurrence is controlled to be the same in every test case. $S \boldsymbol{W} \mathbf{1}$

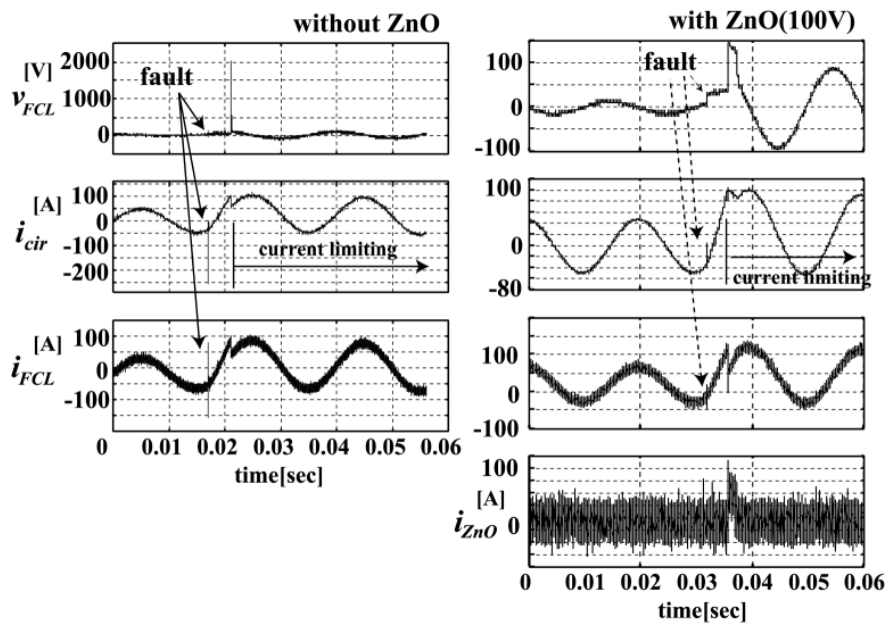

Fig. 4. Experimental result of current limiting operation with and without $\mathrm{ZnO}$ varistor. (Varistor voltage $=100 \mathrm{~V}$.)

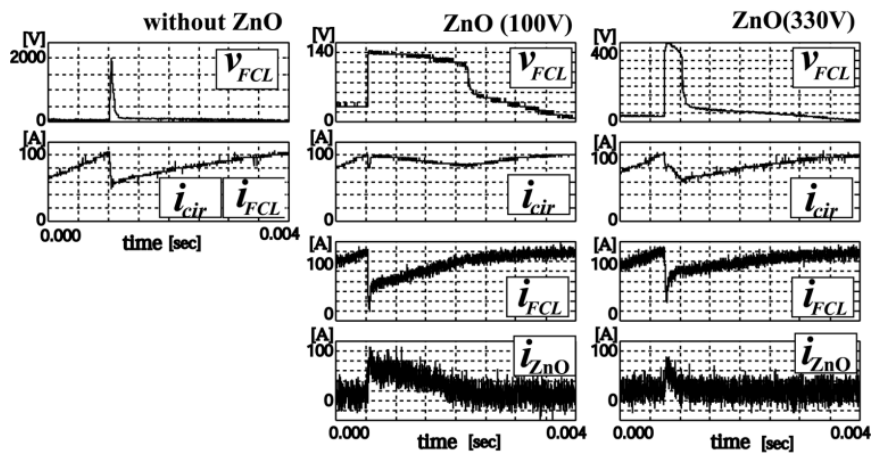

Fig. 5. Experimental result of current limiting operation with and without $\mathrm{ZnO}$ varistor. (Enlarged in time: Varistor voltage $=100 \mathrm{~V}$ and $330 \mathrm{~V}$.)

is open for a few hundred milliseconds to allow the SCFCL to recover from current limiting mode to waiting mode. A $\mathrm{ZnO}$ varistor of several varistor voltages $[\boldsymbol{V v r}=100 \mathrm{~V}, 200 \mathrm{~V}, 330 \mathrm{~V}$, $400 \mathrm{~V}(200 \mathrm{~V} \times 2)$, and $600 \mathrm{~V}(200 \mathrm{~V} \times 3)]$ is installed in parallel to the SCFCL.

The current $i_{\mathrm{ZnO}}$ through the $\mathrm{ZnO}$ varistor, the total circuit current $\boldsymbol{i}_{\mathrm{cir}}$, the voltage $\boldsymbol{v}_{\mathrm{FCL}}$ across the FCL and the current $i_{\mathrm{FCL}}$ through the SCFCL are measured by a sampling oscilloscope through differential amplifiers.

\section{EXPERIMENTAL RESULTS}

\section{A. Over-Voltage Suppression Test}

One of the experimental results is shown in Fig. 4. Fig. 4(a) shows the voltage $\boldsymbol{v}_{\mathrm{FCL}}$ across the SCFCL, the currents $\boldsymbol{i}_{\mathrm{CIR}}$ and $\boldsymbol{i}_{F C L}$ without the $\mathrm{ZnO}$ varistor at the current limiting operation. $\boldsymbol{v}_{\mathrm{FCL}}$ contains a large over-voltage of $2000 \mathrm{~V}$. The voltage and currents with the $\mathrm{ZnO}$ varistor of $\boldsymbol{V}_{v r}=100 \mathrm{~V}$ are shown in Fig. 4(b). The voltage $\boldsymbol{v}_{\mathrm{FCL}}$ is clipped to about $130 \mathrm{~V}$.

Experimental results of current limiting operation with and without a $\mathrm{ZnO}$ varistor, which are enlarged in time, are shown in Fig. 5 (varistor voltage $=100 \mathrm{~V}$ and $330 \mathrm{~V}$ ). It is confirmed that the $\mathrm{ZnO}$ varistor does not affect the trigger current level. The current $\boldsymbol{i}_{\mathrm{ZnO}}$ contains noise due to a measuring problem. However, it can be seen that the $\mathrm{ZnO}$ current only flows in a certain 

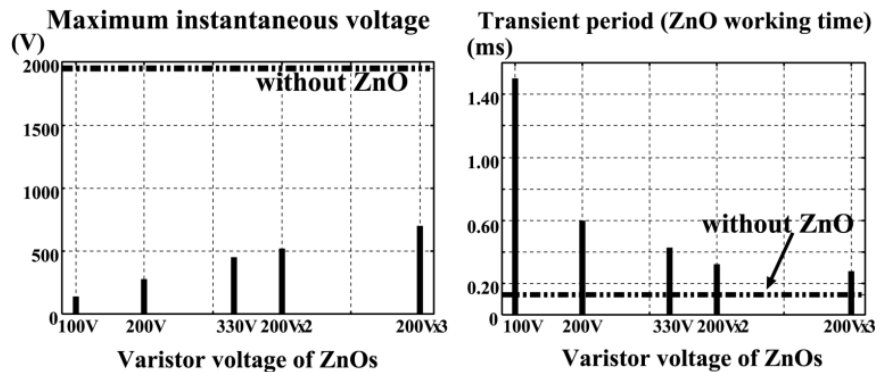

Fig. 6. Maximum instantaneous voltage and transient period for various varistor voltage of $\mathrm{ZnO}$ varistors.

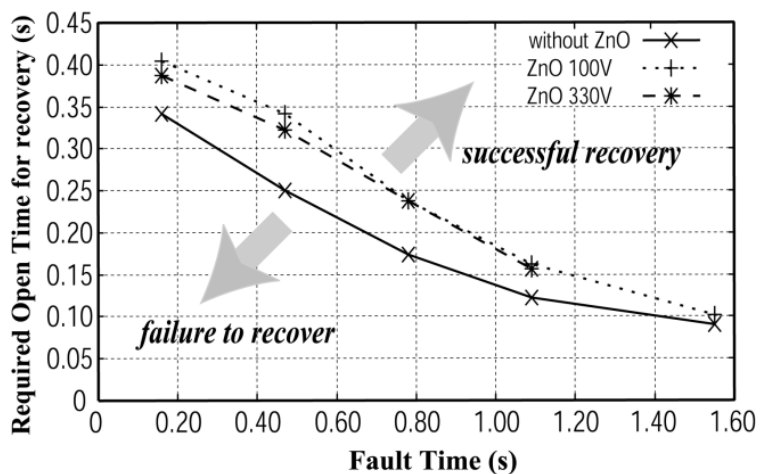

Fig. 7. Recovery time (required open time for successful recovery) versus fault time of SCFCL with and without $\mathrm{ZnO}$ varistor. (Varistor voltage $=100 \mathrm{~V}$ and $330 \mathrm{~V}$.

short transient period, which depends on the varistor voltage of the $\mathrm{ZnO}$ varistor.

\section{B. Maximum Instantaneous Voltage and Transient Period for Varistor Voltage}

The maximum instantaneous voltages and transient periods for various varistor voltages are shown in Fig. 6. The transient voltage at the current limiting operation is successfully suppressed to a certain value according to the varistor voltage of $\mathrm{ZnO}$ varistor. On the other hand, the transient period becomes longer as the varistor voltage become smaller. However, it has less influence on the current limiting characteristics, that is, the trigger current level and the limiting impedance of the SCFCL.

\section{Recovery Time}

The recovery time, which is defined as the required zero current time for recovery from the current limiting mode to the waiting mode, has already been measured and reported on for various fault times, in which the current limiting operation continues [7]. It was reported that the proposed SCFCL has a very short recovery time (less than $450 \mathrm{~ms}$ ) and it decreases as the fault time is longer. The recovery time depends on the temperature of the normal zone of the secondary wire.

The recovery times were measured on the SCFCL with a $\mathrm{ZnO}$ varistor in parallel to study how the $\mathrm{ZnO}$ varistor affects them. The results are shown in Fig. 7. The recovery time becomes longer with the $\mathrm{ZnO}$ varistor than without it by several tens of milliseconds for the shorter fault time. For longer fault times, both recovery times decrease and are close to the same value. From these results, it can be assumed that, with the $\mathrm{ZnO}$ varistor,
TABLE I

ENERGY DISSIPATION AT ZnO DURING THE CURRENT LIMITING OPERATION

\begin{tabular}{r|r}
\hline varistor voltage $(\mathrm{V})$ & dissipation energy $(\mathrm{J})$ \\
\hline 100 & 11.3 \\
200 & 4.5 \\
330 & 4.3 \\
\hline
\end{tabular}

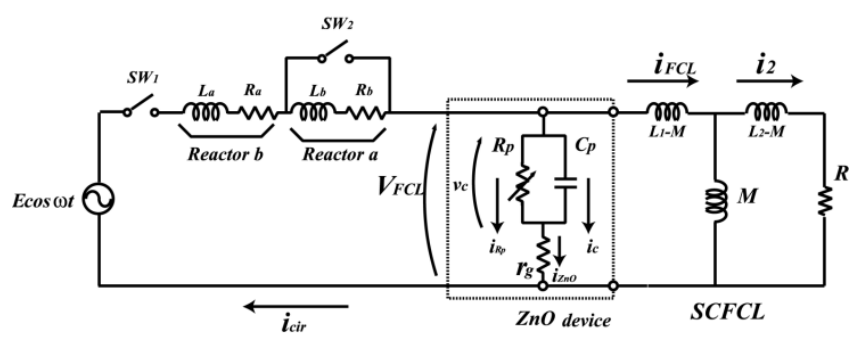

Fig. 8. Equivalent circuit for the simulation.

the temperature of the normal zone of the secondary wire at the beginning of the current limiting event is a little higher locally than that without the $\mathrm{ZnO}$ varistor. After a sufficient fault time, the temperature distribution of the normal zone along the wire is averaged and becomes a flat shape. Therefore, the recovery times with and without a $\mathrm{ZnO}$ varistor become close to the same value.

\section{Energy Dissipation in $\mathrm{ZnO}$ at the Current Limiting Operation}

The energy dissipated in the $\mathrm{ZnO}$ varistor is roughly calculated from the experimental results and listed in Table I. The energy dissipated in the $\mathrm{ZnO}$ varistor becomes larger for smaller varistor voltages. They are sufficiently within the rated capacity of the $\mathrm{ZnO}$ varistors.

\section{Simulation STUdY}

\section{A. Equivalent Circuit}

The equivalent circuit for the simulation is shown in Fig. 8. The equivalent circuit of the $\mathrm{ZnO}$ varistor is surrounded by a dotted square. Capacitance $C_{p}$ and series resistance $\boldsymbol{r}_{g}$ can be neglected for a small $\mathrm{ZnO}$ varistor as used in the tests. The nonlinear resistance $\boldsymbol{R}_{p}$ is modeled as shown in Fig. 2 for varistor voltage $100 \mathrm{~V}$, for example.

The resistance $\boldsymbol{R}$, which is also nonlinear one, depends on the super-normal transition of the secondary superconducting wire. The resistance $R$ is given by use of a simple simulation based on the heat equation. This has already been reported and it was confirmed that the simulation results agree well with the experimental ones [11].

\section{B. Simulation Result}

Fig. 9(a) shows one of the simulation results of the current limiting operation with a $\mathrm{ZnO}$ varistor of varistor voltage $100 \mathrm{~V}$. Fig. 9(b) shows corresponding experimental results. The FCL voltage and the currents agree well with the experimental results. A basic design can be performed by use of the simulation model. The current $\boldsymbol{i}_{2}$ of the secondary coil, which is difficult to measure directly, can be evaluated by use of this simulation. 

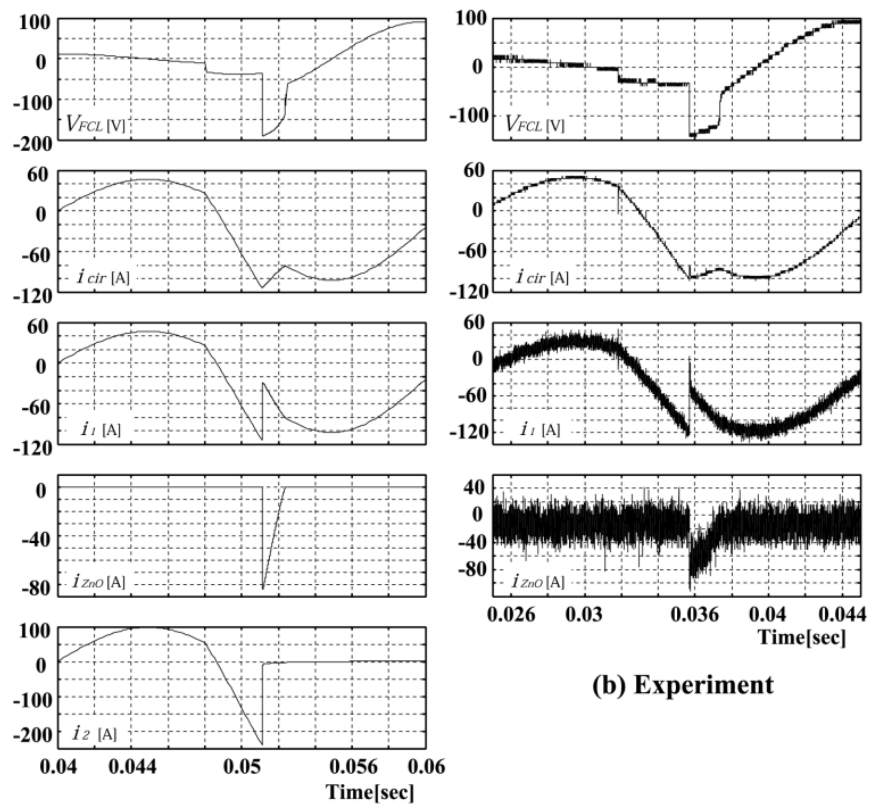

(b) Experiment

(a) Simulation

Fig. 9. Simulation result and corresponding experimental result with $\mathrm{ZnO}$ varistor of varistor voltage $100 \mathrm{~V}$.

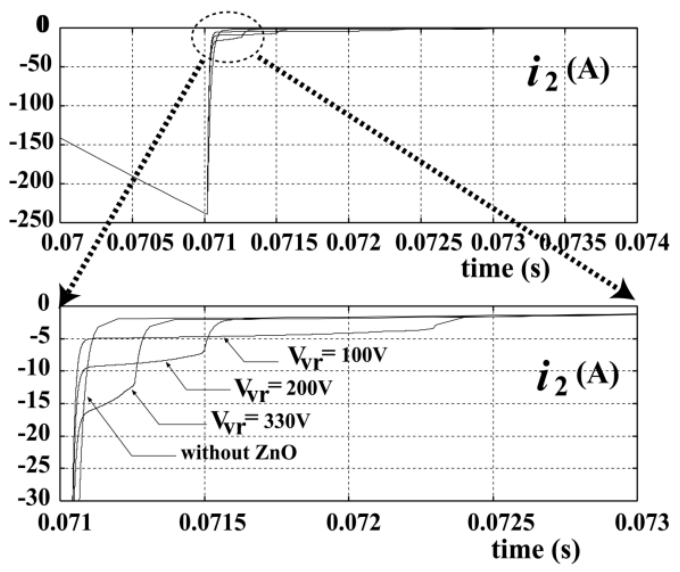

Fig. 10. Magnified wave forms of the secondary coil current at the beginning of the current limitation for various varistor voltages.

\section{Secondary Coil Current at the Voltage Suppression}

The magnified wave forms of the secondary coil current at the beginning of the current limitation are shown in Fig. 10 for various varistor voltages. During the transient period due to the voltage suppression by the $\mathrm{ZnO}$ varistor, the currents $\boldsymbol{i}_{2}$ remain at certain values depending on the varistor voltage. This current may affect the temperature rise in the normal zone of the secondary wire at the beginning of the current limiting event.

\section{CONCLUSION}

The transformer type SCFCL with a $\mathrm{ZnO}$ varistor in parallel was investigated experimentally. The over-voltage across the SCFCL that appears at the beginning of the current limiting event is successfully suppressed by use of the $\mathrm{ZnO}$ varistor.

The trigger current level and the limiting impedance of the SCFCL were not affected by the $\mathrm{ZnO}$ varistor. The recovery time with the $\mathrm{ZnO}$ varistor is just a little longer than without it.

The simulation study on the availability of $\mathrm{ZnO}$ varistor is carried out according to the experimental system. The performance of $\mathrm{ZnO}$ varistor and the secondary coil current at the current limiting operation were confirmed by the simulation results.

\section{REFERENCES}

[1] H. J. Boenig and D. A. Paice, "Fault current limiter using a superconducting coil," IEEE Trans. Magn., vol. 19, pp. 1051-1053, May 1983.

[2] W. Paul, Th. Baumann, J. Rhyner, and F. Platter, "Tests of $100 \mathrm{~kW}$ high-Tc superconducting fault current limiter," IEEE Trans. Appl. Superconduct., vol. 5, pp. 1059-1062, June 1995.

[3] E. Leung et al., "Design \& Development of a 15kV, 20kA HTS fault current limiter," IEEE Trans. Appl. Superconduct., vol. 10, pp. 832-835, Mar. 2000.

[4] B. Gromoll, G. Ries, W. Schmidt, H.-P. Kramer, P. Kummeth, and H.-W. Neumuller, "Resistive fault current limiters with YBCO films-100kVA functional model," IEEE Trans. Appl. Superconduct., vol. 9, pp. 656-659, June 1999.

[5] K. Fujikawa, Y. Shirai, T. Nishikawa, T. Nitta, M. Fukunishi, and T. Shibata, "Experimental study on superconducting fault current limiter with adjustable trigger current level," in Proc. 15th International Conference on MT-15, September 1998, pp. 571-574.

[6] Y. Shirai, K. Fujikawa, T. Kitagawa, M. Shiotsu, H. Hatta, S. Muroya, and T. Nitta, "Study on recovery time of a superconducting fault current limiter with adjustable trigger current level," IEEE Trans. Appl. Superconduct., vol. 11, pp. 2086-2089, Mar. 2001.

[7] Y. Shirai, K. Fujikawa, M. Shiotsu, H. Hatta, S. Muroya, and T. Nitta, "Recovery process of a transformer type superconducting fault current limiter," IEEE Trans. Appl. Superconduct., vol. 12, pp. 880-883, Mar. 2002.

[8] H. Hatta, T. Nitta, S. Muroya, Y. Shirai, and T. Kitagawa, "Experimental study on sudden-short-circuit characteristic of synchronous generator with SCFCL," IEEE Trans. Appl. Superconduct., vol. 11, pp. 2343-2346, Mar. 2001.

[9] H. Hatta, S. Muroya, T. Nitta, Y. Shirai, and M. Taguchi, "Experimental study on limiting operation of superconducting fault current limiter in double circuit transmission line model system," IEEE Trans. Appl. Superconduct., vol. 12, pp. 812-815, Mar. 2002.

[10] K. Fujikawa, Y. Shirai, T. Nitta, K. Hagiwara, and T. Shibata, "Experimental study on adjustability of superconducting fault current limiter with adjustable trigger current level," IEEE Trans. Appl. Superconduct., vol. 9, pp. 1351-1354, June 1999.

[11] Y. Shirai, K. Fujikawa, M. Shiotsu, H. Hatta, and T. Nitta, "Analytical study on recovery operation of superconducting fault current limiter of transformer type," ICEC19, July 2002, submitted for publication. 